\section{Equity, Diversity, Inclusion}

\section{Seattle's "Loud at the Library" Collaboration}

\author{
CIKETTHIA PUGH AND BROOKE DOYLE
}

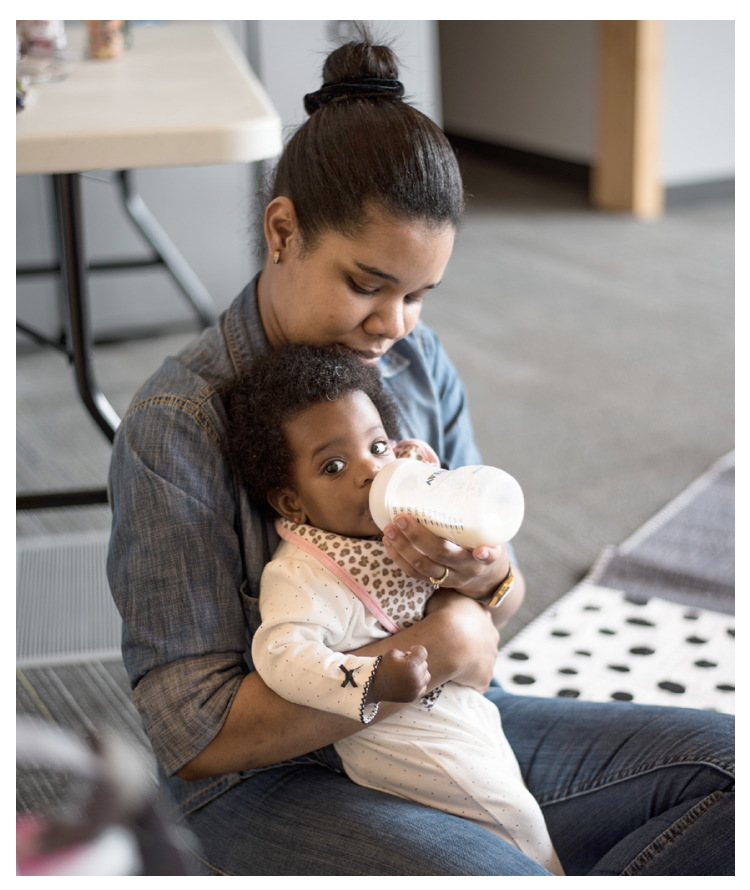

Mom Marimirca Jean-Baptiste and her infant daughter take a break at a Loud @ the Library event.
$\mathrm{P}$ ublic libraries know their storytime programs serve patrons' early learning needs; however, questions arise as libraries feel a sense of urgency to address equity, diversity, and inclusion (EDI) issues.

How can our storytimes attract a more diverse audience? How can we build a collection that represents our community? Is it enough if our shelves feature more authors of color and our storytime attendance climbs?

Efforts toward greater equity are deeply rooted in understanding the distinct needs of communities and the institutional will to change. Leading for equity focuses on outcomes and not outputs. Success is not measured by how many people attend a program. Record storytime attendance numbers tell us nothing about the quality of the experience. Instead we need to think about the outcomes. What has changed as a result of the experience? Is the program aligned with the expressed interest of the community? Are members of the community likely to attend future programs?

Relationships are at the center of our work, and in the absence of those connections, we make assumptions about the interests and emerging needs of communities. This results in practices that continue to tell the same story and imply institutions know what is best instead of listening directly to those we wish to serve.

The work of EDI (see sidebar on page 29 for definitions) is often challenging and evolves over time. Authentic community engagement is about sharing power and focuses on relationships. The Seattle Public Library (SPL) has explored new paths in pursuit of racial equity, and the lessons learned provide insights for all libraries.

Institutions often mistake access and inclusion for equity. Many libraries provide diverse communities access to services and programs that the library has already designed. To reach equity, institutions must share power by forming relationships with people who have not had a seat at the table before and begin to listen to new voices. What emerges from those relationships informs the design of library programs and services.

\section{Pathway for Equitable Programming}

Community engagement provides many opportunities to cultivate new relationships. Traditionally, libraries' approach to developing programming has been limited to internal discussions and planning, but this excludes some critical voices. Communities are dynamic and ever changing. We must start by taking a close look at our common practices in relation to

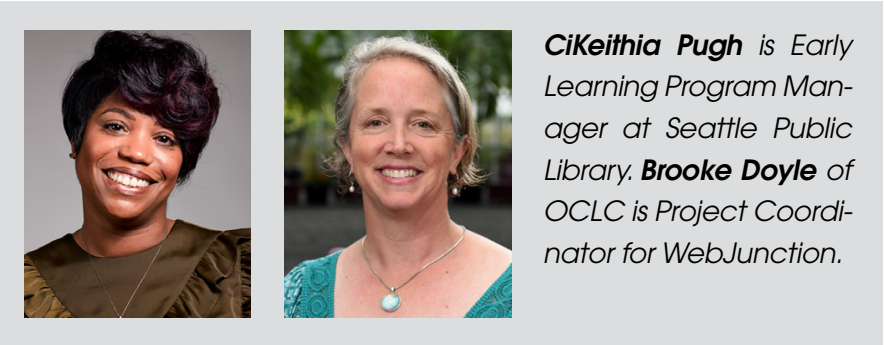


our communities. This simple action is an important beginning step in leading for equity in our libraries. The Pathway for Equitable Programming is a useful tool in this work. ${ }^{1}$

Let's move from theoretical to practical-how does leading for equity look on the ground? We share the illuminating example of community engagement efforts at SPL that led to the creation of a new storytime program, Loud at the Library.

\section{Identify Local Priorities}

SPL implemented a community listening initiative that focused on regional outreach efforts as part of the library's larger Community Engagement Service Priority. The goals were to build connections with individuals and organizations, learn more about existing programs and events in communities, as well as listen for future ideas for library programs.

Those listening sessions highlighted a need and interest for early learning experiences for parents and young children who were receiving home visiting services from the library. Service providers expressed a desire to introduce families to libraries and their available programs and services.

\section{Gather Information}

Libraries are obvious hubs for information and have access to many data resources that add detail to our understanding of a community. However, it is important to investigate what the data is not telling us. What other questions should we be asking internally? Where are the gaps in the sources? What questions do we still have after our analysis? The institutional practice of solely relying on a particular source for more information about a community limits our ability to understand fully the complexity of experiences.

Historically, data has been used to justify the development of policies and practices that disproportionately impact communities of color and low-income communities. Traditional data sources must be balanced with community-led data. SPL had access to all sorts of demographic data about languages spoken and household income for an area, but it did not reveal the patterns and experiences of the residents.

\section{Build Relationships}

By spending time at local public health clinics, SPL staff learned about the Nurse Family Partnership (NFP), a homevisiting service that was already doing great work and had established relationships with their clients at the clinics. The NFP was able to add detail to the demographic data from the library; the nurses shared that the families in their program did not have a connection to the library. The need was clear.
SPL and NFP staff met to brainstorm ideas for an early learning program to introduce parents and young children to the library.

After several meetings, the first Loud at the Library event was designed and held at the Columbia branch to introduce new families to the library. The library and the Partnership had time to build their working relationship and develop a variety of parent-child activities to pilot with the families.

\section{Plan Services}

SPL and the NFP collaboratively came up with the clever name Loud at the Library-families did not need to worry about having quiet, orderly babies when they came for their introduction. Families were encouraged to come as they were; the name also sent a subtle message to library staff that families were welcome as they were.

Each partner identified available resources to support the program and worked together to define roles. SPL offered meeting space, early literacy resources, and a storytime program. The NFP focused on the nutritional component by selecting healthy snacks for the family and led a "make and take" activity at each session. Most important, the nurses' trusted relationships with the families enrolled in the homevisiting program was vital to encouraging them to attend the event. With no established connections to the community, program promotion by the library would have been difficult.

\section{The Loud at the Library Program Plan}

\section{- Welcome, Introductions, Social Time, Snack}

- Open-ended play

- Storytime led by library staff

- Optional parent-led storytelling, such as sharing stories and songs from childhood memory in their language.

- Parent Circle-Social time for connecting with library staff and nurses. Staff could share community events and resources and learn more about what topics interest them.

- Library Orientation-including tours, card signups, and staff meet-and-greet.

\section{Deliver Services}

The first Loud at the Library program had only two families, but library staff considered two to be a success! It was the beginning of a trusting partnership where families could feel welcome and learn about the library. For the second program, the NFP offered more reminders, made personal phone 
calls, and assured clients that familiar faces they knew from the NFP would be there. The nurses did a lot of one-on-one engagement and encouragement to assure their clients that they would receive something for coming, that it would be fun, and that food and door prizes were offered. The second session had eight attendees. The program grew from those two events to six programs annually.

\section{Evaluate Services}

The families, the library, and the nurses reflected throughout the process on what was working and what needed to change. The desired outcome identified on the joint logic model and evaluation plan was simply that NFP families feel welcome in the library. Survey analysis as well as anecdotal evidence indicate outcomes were met.

Some parents wanted to lead activities or share a skill (for example, bilingual parents wanting to co-present a storytime), which was an unanticipated but wonderful outcome. Parents began to co-design the program; at one program, for example, a parent taught the group yoga. In the future, the library program manager would like to become technical support as the parents and branch staff own the program-the dream is to offer compensation to the parents who are co-leading.

Leading for equity and authentic community engagement takes time. SPL began its community listening process in May 2016, and the first Loud at the Library program was offered in August. Now, Loud at the Library is a robust part of the library's offerings, but it took patience.

Think about the community groups in your service area with which your library has not developed relationships. Focus on building relationships with those communities. You will need to show up again and again and build trust over time. Find the trusted community organizations and work with them to build true partnerships where power is shared. \&

To learn more, visit WebJunction's free Supercharged Storytimes self-paced course (https://oc.lc/supercharged-course). Module 5 led by CiKeithia Pugh focuses on Storytimes through an Equity Lens. The module includes many rich resources such as a Library Walkthrough Checklist among others.

\section{Reference}

1. "Pathway to Equitable Programming," WebJunction, 2018, www.webjunction.org/content/dam/WebJunction

/Documents/webJunction/2019-01/Pathway-to

-Equitable-Programming.pdf.

\section{Clarifving Equity}

Building a shared understanding of equity helps to construct an internal framework that informs our work. Making the distinction between equity, diversity, and inclusion is important so that we're clear about how we apply the terms to our work.

- Equity is another way of saying fairness and justice. Think of equity as not simply something to aspire to; for equity to be achieved and sustained, it needs to be considered a structural and systemic concept.

- Diversity includes all the ways people differ, and it includes all the different characteristics that make one individual or group different from another. It recognizes everyone and every group as valuable. The term is often used to include aspects of race, ethnicity, gender, sexual orientation, class, and much more. There can be plenty of diversity without equity. ${ }^{2}$

- Inclusion means bringing traditionally excluded individuals and groups into activities and decisionmaking.

Only focusing on diversity and inclusion is shortsighted. Leading for equity allows us to move from a one-size-fits-all approach to focusing on how to close gaps and provide opportunity and power to traditionally marginalized communities.

\section{References}

1. Race Equity and Inclusion Action Guide (Baltimore: Annie E. Casey Foundation, 2014), www.aecf.org/m/resourcedoc /AECF_EmbracingEquity7Steps-2014.pdf.

2. Monisha Kapila, Ericka Hines, and Martha Searby, "Why Diversity, Equity, and Inclusion Matter," Independent Sector, October 6, 2016, https://independentsector.org/resource /why-diversity-equity-and-inclusion-matter. 